\title{
RIGHT-SIDED PERFORATED ASCENDING COLONIC DIVERTICULUM MIMICKING ACUTE APPENDICITIS
}

\author{
Edina Bilic Komarica, Zlatan Zvizdic \\ Clinic of Anaestesiology, Clinical Center of University of Sarajevo, Sarajevo, Bosnia and Herzegovina \\ Corresponding author: Edina Bilic-Komarica, MD, Msc. Clinic for Aaestesiology, CCUS, 71000 Sarajevo, B\&H. E-mail: ebilic@gmail.com
}

\section{Case report}

ABSTRACT

Perforation of the colonic diverticulum is a common reason for emergency laparotomy, especially in older people but is rare in the younger population. While perforation of the sigmoid diverticulum is very common, perforation of the ascending colonic diverticulum is a very rare event. For this reason, the divereticulitis is usually discovered unexpectedly

at surgery for suspected appendicitis Key words: Righ-sided diverticulitis, perforation, laparotomy, surgery.

dium was $142 \mathrm{mmol} / \mathrm{L}$; potassium was $3.1 \mathrm{mmol} / \mathrm{L}$; haemoglobin was $129 \mathrm{~g} / \mathrm{dL}$; white cell count was 14.8 x 109/L, liver function were normal.

She was previously healthy and had no significant past medical history. A provisional diagnosis of acute appendicitis was made. At operation, through a Mc Burney incision, the appendix was found to be normal but a $3 \mathrm{~cm}$ gangrenous and perforated ascending colonic diverticulum was found. The patient underwent an appendectomy with isolated diverticulectomy and recovered uneventfully.

\section{DISCUSSION}

Diverticular disease is a common disorder in Western countries (5). Diverticula can occur throughout the colon but are most common near the end of the left colon referred to as the sigmoid colon in Western countries. On the other hand, in Asia the diverticula occur mostly on the right side of the colon (5). The etiology of diverticular disease is multifactorial and not completely understood but it is now known that low dietary fiber intake, cigarette smoking, alcohol intake, corticosteroids, altered collagen structure in the bowel, increased acetylcholine activity in the sigmoid colon, and aging may be risk factors
(6, 7). Approximately $75 \%$ of patients remain symptom-free during their lifetime. The remaining 25\% of patients develop complications in the form of infection (diverticulitis), rectal bleeding, constipation, diarrhea, abdominal cramps, and even colonic obstruction (7). Diverticula localized to the right colon occur at a rate of 6.6 to $14 \%(10)$. On the basis of etiologic and pathologic features, two types of diverticula have been described in the right colon: multiple diverticula and solitary diverticulum of the cecum $(8,10)$.

The most common clinical presentation of right-sided colonic diverticula is an acute inflammatory complication which is difficult to distinguish from other causes of right iliac fossa pain (9). Preoperative diagnosis of appendicitis is almost always made in these patients (10). Other pathology may mimic right side diverticulitis including colonic malignancy, inflammatory Crohn's mass, perforated foreign body reaction or ileocaecal tuberculosis.

Ultrasound has been evaluated in the diagnosis of right-sided diverticulitis and demonstrated a sensitivity of $91.3 \%$, a specificity of 99.8\% and overall accuracy of $99.5 \%$ in the diagnosis of righ-sided diverticulitis (11). (Figure 1). However, al- blood results were as follows: $\mathrm{pH}$ was $\mathrm{xx}$ with a base excess of $\mathrm{XX}$, so- 

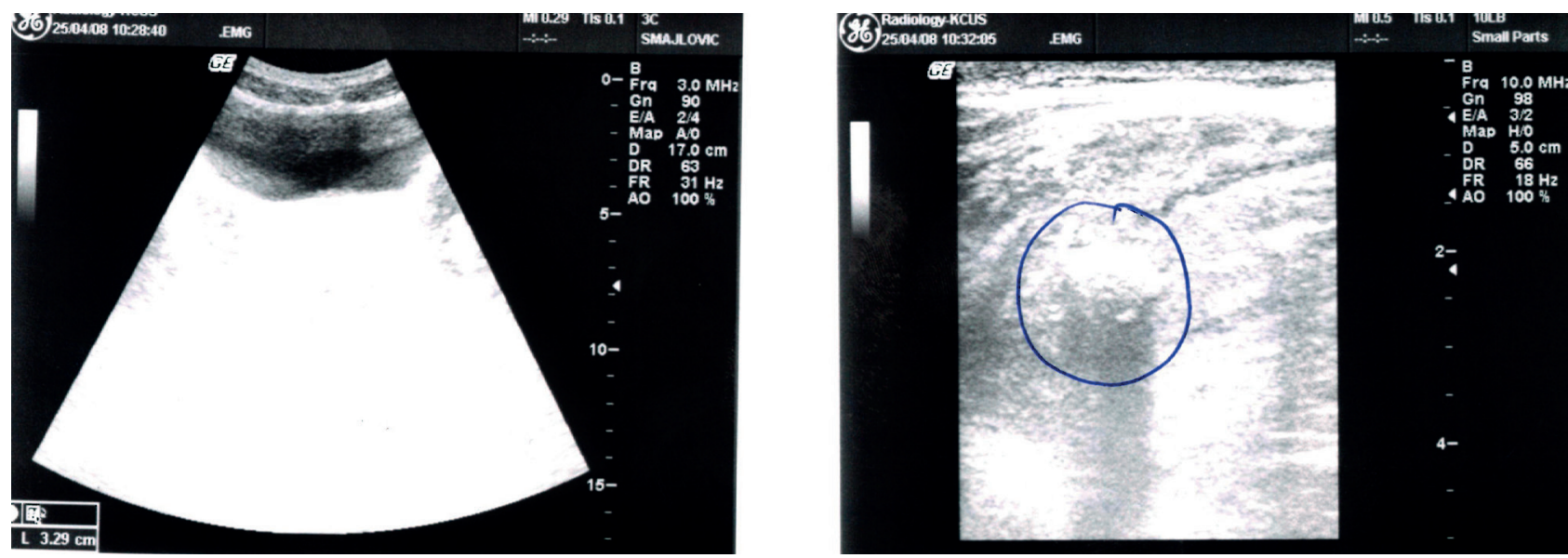

Figure 1. Ultrasound examination of right-sided perforated ascending colonic diverticulum MImicking acute appendicitis

though ultrasound is non-invasive and widely available, operator dependency may limit its accuracy, especially in Western countries where experience of caecal and ascending diverticulitis is limited. In our case, because of our strong clinical assumption that our patient had acute appendicitis no further pre-operative imaging studies were performed. Surgical resection varies from isolated diverticulectomy, ileocaecal resection and right hemicolectomy (12). In our case, isolated diverticulectomy with appendectomy was the method of choice of surgical treatment with good outcome.

In conclusion, preoperative diagnosis of right-sided colonic diverticulitis is important in the timely evaluation of treatment modalities, but not always possible. Although ultrasound is non-invasive and widely available, operator dependency may limit its accuracy, especially in Western countries where experience of caecal and ascending diverticu- litis is limited. During the surgical procedure, if the diagnosis of acute appendicitis is in doubt, further exploration should be performed. In most cases, when it excludes other possible pathologies, isolated diverticulectomy is adequate treatment.

Conflict of interest: none declared.

\section{REFERENCES}

1. Lo CY, Chu KW. Acute diverticulitis of the right colon. Am J Surg. 1996; 171: 244-246.

2. Tonelli F, Di Carlo V, Liscia G, Serventi A. Diverticular disease of the colon: diagnosis and treatment. Consensus Conference, 5 th National Congress of the Italian Society of Academic Surgeons. Ann Ital Chir. 2009; 80(1): 3-8.

3. Jang HJ, Lim HK, Lee SJ, Choi SH, Lee $\mathrm{MH}$, Choi MH. Acute diverticulitis of the cecum and ascending colon: thin-section helical CT findings. AJR. 1999; 172: 601-604.

4. Katz DS, Lane MJ, Ross BA, Gold BM, Jeffrey RB Jr, Mindelzun RE. Diverticulitis of the right colon revisited. AJR 1998; 171: 151-156.

5. Salzman H, Lillie D. Diverticular disease: diagnosis and treatment. Am
Fam Physician. 2005; 72(7): 1229 1234.

6. Floch $\mathrm{MH}$, White JA. Management of diverticular disease is changing. World J Gastroenterol. 2006; 12(20): 3225-3228

7. Bordeianou L, Hodin R. Controversies in the surgical management of sigmoid diverticulitis. J Gastrointest Surg. 2007; 11(4): 542-548.

8. Funicello A, Fares LG 2nd, Oza K, Valaulikar G, Ernits M. Right-sided diverticulitis - surgical and nonsurgical treatment: two case reports and review of the literature. Am Surg. 2002; 68(8): 740-742.

9. Giuffrida MC, Gelarda E, Mezzatesta P, Macaluso A, Siragusa G. Diverticula of right colon. The diagnosis and treatment of complications. Minerva Chir. 1997; 52(12): 1503-1512.

10. Nirula R, Greaney G. Right sided diverticulitis; a difficult diagnosis. An Surg 1997; 63(10): 871-873.

11. Chou YH, Chiou HJ, Tiu CM, Chen ID, Hsu CC, Lee CH, Lui WY, Hung $\mathrm{GS}, \underline{\mathrm{Yu} C}$. Sonography of acute right side colonic diverticulitis. Am J Surg. 2001; 181(2): 122-127.

12. Zonca P, Jacobi CA, Meyer GP. The current view of surgical treatment of diverticular disease. Rozhl Chir. 2009; 88(10): 568-576. 